\title{
Gestión del sector minero en el ámbito colombiano y su relación entre el accionar gubernamental y empresarial $^{*}$
}

\author{
Management of the mining sector at the national level and \\ the relationship between government and business actions
}

Resumen

A medida que la economía avanza, los Estados se ven obligados a innovar en sus medios de producción con el fin de generar estrategias competitivas que permitan su incursión en la esfera del mercado mundial. Una de estas pericias tenidas en cuenta por Colombia ha sido la incursión de la minería en gran parte de sus departamentos, lo que ha generado una fuerte ola de inversión tanto extranjera como nacional ante este sector económico. El presente documento pretende caracterizar la gestión de la industria minera en el ámbito colombiano y su relación entre el accionar gubernamental y empresarial, lográndose esto a través de una revisión y análisis documental. El territorio colombiano se encuentra bastante desprotegido por el Estado, lo que ha generado fuertes repercusiones en el desarrollo de esta actividad en las áreas donde se ejecuta.

Palabras clave: minería, gestión gubernamental, gestión empresarial, Colombia

\begin{abstract}
As the economy advances, States are forced to update their means of production in order to generate competitive strategies that allow its foray into the sphere of the world market. One of these skills considered by Colombia, it has been the incursion of mining in many of its departments, which has generated a strong wave of investment both foreign and domestic to this economic sector.This document aims to characterize the management
\end{abstract}

\footnotetext{
* Artículo de investigación realizado en el proyecto «Cartografía socio-ambiental, perfil epidemiológico en menores de 5 años y estrategia educativa en territorios donde empieza a configurarse la minería como actividad económica: caso Occidente Antioqueño, 2015/2016», financiado por colCiencias en el marco de la convocatoria 657 para proyectos de ciencia, tecnología e innovación en salud.
} 
of the mining industry in Colombia and the relationship between government and business actions, this being achieved through a review and document analysis. The Colombian space is fairly unprotected by the state territory, which has generated strong impact of this activity in the areas where it runs.

Keywords: mining, governance, business management, Colombia

\section{INTRODUCCIÓN}

La minería en Colombia ha pasado de ser un medio de subsistencia terciario, llevado a cabo por comunidades étnicas y campesinas de una manera artesanal y a pequeña escala, a convertirse en una de las industrias más significativas del país. Actualmente, este sector representa una de las cinco llamadas «locomotoras de desarrollo» de la nación, dentro de las cuales se destacan a su vez: infraestructura, vivienda, agricultura e innovación.

Según el Servicio de Información Indígena (SERVINDI) (2004: 1), hoy en día, el sector minero representa un factor de alta importancia para la economía de una gran cantidad de países latinoamericanos, lo que ha convertido a dicha industria en una de las más influyentes en cuanto a la propulsión de Inversión Extranjera Directa (IED), siendo este uno de los argumentos para justificar el pensamiento de que la minería es la más indicada para solventar las necesidades internas y la deuda externa de estas naciones. Tal es el caso de Colombia, cuyo Estado ha transformado las críticas ante este tipo de actividad en un ataque contra la inversión privada, patrimonio y provecho social.

Por otra parte, Quiroga (2012), con respecto al contexto colombiano, esgrime que desde el año 2000 el término «minería» ha suscitado dos posturas. Por un lado se hallan los que defienden esta actividad como propulsora de desarrollo industrial y monetario, y por el otro se encuentran los diversos movimientos sociales y ambientalistas, quienes enumeran los grandes impactos que este tipo de labor ha generado en el ámbito territorial del país, especialmente para los grupos étnicos y campesinos. Del mismo modo, dicho autor demuestra que ha sido tal la importancia que ha suscitado este sector a nivel nacional, que mediante frases como «locomotora de crecimiento» $\mathrm{O}$ «locomotora de desarrollo», este método productivo ha ganado un considerable impulso, tal como se ha presentado en los dos últimos planes de gobierno del presidente Juan Manuel Santos y durante los mandatos de Álvaro Uribe (el anterior presidente de Colombia).

Cuando se habla del sector minero, sobresalen cuatro ejes temáticos claves al momento de abordar este tipo de industria. Por un lado, se en- 
cuentra el Gobierno, encargado de expedir el marco normativo y velar por una adecuada gestión de esta actividad en cuanto a su verificación y control. Por el otro lado se encuentran las multinacionales y demás instituciones o individuos que poseen concesiones de exploración y explotación y son los delegados de ejecutar esta acción. De la misma manera, se distingue la comunidad como otro de los ejes estructurales en esta industria, ya que es ésta la que directamente recibe el impacto tras el arribo de dicha labor a sus territorios. Por último, pero no menos importante, se ubica el recurso natural, que facilita la extracción de los minerales y propicia la base de los diferentes medios de subsistencia de la comunidad.

Tener en cuenta estos cuatro ejes es fundamental al momento de estudiar la gestión del sector minero por parte de las multinacionales y del Gobierno, la cual se ve reflejada no solo en la economía del país, sino también en el impacto de esta actividad en la vida de las poblaciones donde se desarrolla y de sus recursos naturales. Contexto este último que, lamentablemente, no es muy tenido en cuenta en Colombia ya que, como se evidenciará más adelante, sobresale una inadecuada gestión por parte del sector empresarial y a esto se le suma una débil fiscalización a manos del gobierno, contribuyendo así a que la ejecución de dicha industria sea altamente nociva para la subsistencia y desarrollo ambiental del territorio. En este documento se pretende, pues, caracterizar la gestión del sector minero en el ámbito nacional y su relación entre el accionar gubernamental y empresarial.

\section{METODOLOGÍA}

Para caracterizar la gestión del sector minero en el ámbito nacional y su relación entre el accionar gubernamental y empresarial, se llevó a cabo una exploración y análisis documental, la cual se dio a través de la consulta de diversas fuentes bibliográficas referentes a la temática objeto de estudio, para esto se tuvieron en cuenta escritos como: periódicos en web, libros, artículos de investigación, blogs de información y demás documentos electrónicos que se consideraron relevantes en cuanto a su aporte a la estructura del documento, los cuales fueron respectivamente sistematizados y estudiados. 


\subsection{Estrategias metodológicas}

Esta indagación se ejecutó teniendo en cuenta dos fases: la primera de tipo investigativo, que permitió la adquisición de la información tendente a consideración para su validez y análisis, y en la segunda fase un análisis de tipo deductivo, que permitió el tratamiento de la información obtenida en la primera etapa.

\subsection{Procedimiento}

Una vez llevadas a cabo la primera y segunda fases, los documentos obtenidos y considerados relevantes para la temática a estudiar se sometieron a su respectivo análisis y reflexión, lo cual se dio por medio de la estructura y diseño de cuatro categorías de investigación, nombradas de la siguiente manera: contexto colombiano en el auge de la minería y aportes económicos y laborales de este sector industrial, multinacionales mineras y su principio de Responsabilidad Social Empresarial, situación actual del sector minero en la esfera regional, y el gobierno y su gestión ante la industria extractiva.

\subsection{Resultados}

Como bien se mencionó antes, al momento de hacer un estudio sobre la caracterización de la gestión del sector minero en el ámbito nacional, se hace indispensable contextualizar el entorno colombiano en cuatro esferas: la empresarial, la gubernamental, la poblacional y la ambiental. Debido a que las dos primeras son las encargadas de producir y velar por una adecuada ejecución de este sector, una incorrecta gestión por su parte supone fuertes repercusiones tanto ambientales como poblacionales. A continuación, se dará a conocer la relación de estos cuatro ejes por medio del análisis y la reflexión de cinco categorías tomadas en cuenta durante la indagación y recolección de la información. 
1.4. Contexto colombiano en el auge de la minería y aportes económicos y laborales de este sector industrial

De acuerdo con el portal web Colombia.com, este país ocupa el cuarto lugar de las economías más grandes de América Latina después de Brasil, México y Argentina; mientras que a nivel internacional se encuentra dentro de las 31 mayores del mundo. A su vez, Colombia forma parte de las denominadas economías emergentes con alto potencial de desarrollo, las cuales son denominadas CIVETs (Colombia, Indonesia, Vietnam, Egipto, Turquía y Suráfrica). Dentro de las principales bases productivas del país, sobresale principalmente la de bienes primarios para la exportación y la producción de bienes de consumo para el mercado interno, siendo sus primordiales actividades económicas la agricultura, la pesca, la silvicultura y la minería. Esta última representa a nivel gubernamental e industrial la gran oportunidad nacional para solventar las necesidades internas y propiciar un aliciente económico en el ámbito de deuda externa y visibilización internacional. Al mismo tiempo, la minería ha facilitado el acrecentamiento del Producto Interno Bruto en las últimas décadas, aportando, de acuerdo con Saade (2013) un incremento del 0,16\% al 0,93\% entre los periodos de 1990-2003 y 2004-2010.

El potencial geológico de Colombia y su alta riqueza en cuanto a reservas naturales, han favorecido altamente la propulsión de este tipo de economía en el ámbito nacional. Según el Ministerio de Minas y Energía (2009), los principales minerales de gran interés en el proceso extractivo colombiano son el carbón (ocupando el país uno de los primeros lugares a nivel mundial en cuanto a su exportación), la producción de metales y piedras preciosas como oro, plata, platino, esmeraldas, y de minerales metálicos como níquel, cobre, hierro, manganeso, plomo, zinc y titanio; abarcando geográficamente este sector industrial cerca de 250 municipios del territorio nacional; contexto que, de acuerdo con Malaver (2002), ha propiciado en las últimas décadas el uso y la transformación de recursos naturales propios del país, ampliando significativamente su contribución a las exportaciones industriales en cuanto a la exportación de minerales metálicos y no metálicos.

Es tal la significancia que se le ha dado a la inclusión de esta actividad de carácter extractivo en el país, que basta con revisar los altos índices de expedición de licencias y títulos mineros. Las cifras son tan abrumadoras que el sector agrario, el cual ha sido la base económica del país por siglos, 
ha pasado a un segundo plano en cuanto a otorgamiento de tierras y a nivel productivo:

El auge de la minería se refleja en la dinámica de otorgamiento de licencias. Entre 2000 y noviembre de 2010 el Ministerio de Minas otorgó 7.264 títulos mineros y tramitó 17.479 solicitudes en toda la geografía nacional; mientras la superficie que se contrató rebasó las 5,8 millones de hectáreas, área superior a las extensiones dedicadas a la actividad agrícola del país (PNUD, 2011: 45).

Según Bermúdez, Rodríguez y Roa (2012:3), el sector minero colombiano, a pesar de poseer un retraso en cuanto a las esferas corporativas, de formalización y afianzamiento industrial, en las últimas décadas ha incrementado altamente sus niveles de inversión. Esta realidad, debido a las políticas de estímulo a la Inversión Extranjera Directa, ha generado que esta actividad ocupe el segundo renglón en las exportaciones nacionales con productos como el carbón, el ferroníquel y el oro:

La Inversión Extranjera Directa (IED) en el sector aumentó en un $74 \%$ pasando de 1.783 a 3.094 millones de usD\$ de 2006 a 2009 (Bases del DNP, 2010-2014). Para el año 2009, se tiene un conjunto de empresas extranjeras mineras inversionistas en Colombia, de un total de 9 países. Entre estos sobresalen las empresas de origen canadiense, con un total de 28 empresas provenientes de ese país, que representan el 51\% de las empresas extranjeras en Colombia (Bermúdez, Rodríguez y Roa, 2012:3).

Pese a lo anterior, dichos autores ratifican que esta industria simboliza unas tasas mínimas en el incorporado de actividad productiva de la nación, comparando este sector en términos del PIB con relación al PIB total nacional:

En la última década, pasó de representar el 1.82\% en el año 2000 al 2.36\% en el año 2009 [...] A pesar de que el sector tuvo un crecimiento significativo en esta década, su baja participación en el PIB total advierte sobre sus pocas posibilidades de constituirse en un sector que dinamice la economía nacional, en los términos planteados en la apuesta gubernamental (Bermúdez, Rodríguez y Roa, 2012: 3).

Con respecto al párrafo anterior y a la alusión que hacen sus autores sobre la poca posibilidad de dinamismo económico nacional que propicia esta industria, es importante tener presente que en el ámbito laboral este sector tampoco se ha caracterizado por patrocinar mayores oportunidades: «Uno de los sectores clave a los cuales el país le ha apostado gran parte de sus esfuerzos políticos y de seguridad, como lo es la explotación de minas y canteras, ha aportado al crecimiento del país el $10 \%$, pero en términos de empleo tan solo un 1,4\%» (sic) (García, 2014). Este hecho, de acuerdo con 
Fernández y Valencia (2010), está relacionado «con una política fiscal no al servicio de la producción, empleo y distribución de ingreso, sino de la provisión de un clima de negocios que reduzca las incertidumbres de los inversionistas sobre el futuro de sus negocios».

Sumándosele a esto los riesgos laborales a los que se enfrentan los operarios que ocupan cargos en este sector. Según un artículo de prensa del portal web Portafolio, Colombia se caracteriza por poseer altos índices en materia de accidentalidad dentro de la industria mineroenergética: «En la última década han fallecido cerca de mil personas en más de 700 emergencias presentadas en operaciones mineras legales e ilegales. La mayor mortalidad se da en minas subterráneas de carbón» (Celedón, 2015). De acuerdo con dicha publicación, la cual extrajo sus cifras del Grupo de Seguridad y Salvamento Minero de la Agencia Nacional de Minería (ANM), en la última década se han producido cerca de 999 fallecimientos en 795 emergencias, llamando la atención que el $75 \%$ de los incidentes registrados entre los años 2005-2015 hagan referencia a accidentes acaecidos en minas legalmente constituidas.

A lo anterior, se le pueden añadir las altas cifras de absentismo laboral por causa médica de trabajadores mineros de las áreas operativas, las cuales de acuerdo con un estudio llevado a cabo por Vásquez (2011), entre el 1 de enero y 31 de diciembre de 2011 en una empresa colombiana de carácter minero se presentaron 13 episodios de ausencias laborales, las cuales estaban relacionadas con episodios de enfermedad y principalmente el $77 \%$ de los casos en trabajadores menores de 34 años. Para clarificar un poco más el panorama que se vivencia dentro de este tipo de industria, a todo lo ratificado en el párrafo anterior, se le añade la cuestión salarial. De acuerdo con Iregui, Melo y Ramírez (2011), un operario del sector minero gana en promedio entre $\$ 981.372$ y $\$ 1.075 .992$ (ni siquiera dos salarios mínimos legales vigentes colombianos, registrado para este año en \$689.454). Esta situación es alarmante puesto que este monto de dinero, se debe repartir entre el pago de arriendo, servicios, educación de hijos, y demás factores de manutención. Colombia, actualmente cuenta con un Índice del Precio del Consumidor (IPC) del 9\%, cifra que denota las constantes alzas de productos básicos para los hogares colombianos como la papa, el arroz, el azúcar, las verduras y las frutas de acuerdo con un reporte dado por el diario El País (García, 2016).

Todo lo anterior indica que no es inversamente proporcional el otorgamiento de licencias mineras y la inversión extranjera ante el desarrollo de una nación, o al menos ese no es el caso para Colombia. Como se puede 
constatar, pese a tener una constante titulación para diferentes empresas del sector, profundo apoyo gubernamental y poseer un alto índice de IED, los resultados no se han visto reflejados en el patrimonio nacional, ya que la economía prácticamente ha crecido a niveles mínimos, si se tienen en cuenta los impactos sociales y ambientales que genera dicha industria.

\title{
1.5. Multinacionales mineras y su principio de Responsabilidad Social Empresarial
}

En la Ley N. 1382 (Gobierno de Colombia, 2010), expedida por el Congreso de la República de Colombia, se define el concepto de Responsabilidad Social Empresarial (RSE) en el sector minero como:

\begin{abstract}
Las empresas mineras promoverán y efectuarán actividades de responsabilidad social, en un marco de desarrollo humano sostenible, que propendan por la promoción de comportamientos voluntarios, socialmente responsables, a partir del diseño, desarrollo y ejecución de políticas, planes, programas y proyectos que permitan el logro de objetivos sociales de mejoramiento en la calidad de vida de la población y la prevención y reparación de los daños ambientales en las regiones, subregiones y/o zonas de su influencia (Ley N. ${ }^{\circ} 1382$, Congreso de Colombia).
\end{abstract}

Gonzales (2014: 186) argumenta que en los países en vía de desarrollo el tema de la RSE ha tomado gran fuerza mediante la instauración de requerimientos que faciliten la competencia a nivel mundial, lo cual se ha manifestado a través de los «tratados de comercio internacional». De esta manera, se establece el deber de los titulares de proyectos extractivos para que estos se ejecuten bajo un enfoque social, favoreciendo mejores condiciones de empleo, calidad de vida, sostenibilidad ambiental y defensa del recurso natural, brindando un impacto positivo en la comunidad de forma inmediata y futura.

Según la Unidad de Planeación Minero Energética (UPME) (2013: 5), desde el año 2000, las empresas mineras colombianas han comenzado a formar alianzas, una de ellas es el resultado de la organización nombrada: Sector de la Minería a Gran Escala (SMGE), entidad que agrupa las trece empresas de exploración y explotación más importantes del país en cuanto a minería de carbón, oro y ferroníquel. En el área de la RSE, esta institución ha creado cuatro frentes de trabajo: el primero consiste en el compromiso de cada multinacional de cumplir y aceptar de manera voluntaria ciertos objetivos, los cuales abarcan tres convenios importantes: cumplimiento de estándares internacionales, la ejecución de la actividad con la implementación de progra- 
mas que aborden la prevención, mitigación, compensación y restauración natural y el aporte al desarrollo socioeconómico de las poblaciones donde llevan a cabo su labor. El segundo frente aborda la temática de la inversión financiera a nivel social y ambiental de las empresas en las comunidades afectadas. Y el tercer frente aborda una estrategia denominada «Alianza Social para la formalización», la cual permite la intervención de las empresas para manejar los riesgos generados por la acción ilegal llevada a cabo por organismos al margen de la ley.

En base a lo anterior, y para poder brindar un análisis de la gestión empresarial en el marco del sector minero energético, se hace importante destacar el ciclo PHVA (planear, hacer, verificar y actuar), el cual debe fundamentar el accionar empresarial, debido a que es un instrumento que permite alcanzar el mejoramiento continuo de todo tipo de organización. Si se adentra en el marco de lo estipulado en el concepto de RSE, se puede constatar que la ejecución de esta herramienta solo se queda en el planear, puesto que como se pudo apreciar, tiene cuatro frentes de trabajo (mencionados en el párrafo anterior), los cuales se conciertan de una manera adecuada demostrando que las intenciones de este tipo de industria son pertinentes en cuanto a su responsabilidad social y de sostenibilidad ambiental. El verdadero problema radica en el accionar, ya que si bien este sector argumenta que llevan a cabo cada uno de los programas planteados, la percepción de la comunidad y los hechos evidencian lo contrario:

El entrevistado [A1], comenta que «estas trece empresas invierten cerca de 64 mil millones (COP) al año, eso es mucho más del presupuesto de muchas entidades del Estado, en estrategias de RSE voluntarias, y en estrategias de protección ambiental, unos, 164 mil millones (COP)».Aun así, y de acuerdo con el entrevistado [A1], la percepción de las comunidades y el público en general, es que las empresas mineras no hacen inversión social en las comunidades donde laboran, y ocasionan daños irreparables a los recursos naturales (sic) (UPME, 2013: 6).

Con respecto a esto último, y retomando el ciclo PHVA y su importancia en el ámbito de una adecuada gestión institucional, queda el verificar y el actuar. Aquí es donde entran en juego los organismos de control y vigilancia: si el sector minero lleva a cabo lo planteado en materia de Rse, ¿por qué la comunidad manifiesta lo contrario?, ¿qué acciones ha implementado el gobierno para constatar dichas cifras y velar por el adecuado proceso? En relación a estas preguntas, Padilla (2011), en su escrito titulado «Impactos ambientales y socioeconómicos de la minería», hace alusión a cómo los países que han implementado el modelo de RSE han tenido que fortalecer sus capacidades fiscalizadoras, ya que en la mayoría de los casos estas prác- 
ticas han servido como «telones» para ocultar problemáticas sociales y ambientales generadas a raíz de esta actividad extractiva: «Hay otros países que aún aplican la táctica del avestruz, lo que otorga una importante ventaja en externalización de efectos negativos a las actividades mineras» (Padilla, 2011).A su vez, dicho autor identifica una serie de críticas recurrentes en materia de RSE, las cuales provienen de comunidades aledañas a proyectos mineros, y se agrupan como sigue:

Es una forma de publicidad empresarial. No constituye necesariamente una forma de responsabilidad jurídica por ser voluntario. Las sanciones son indirectas e influyen en los accionistas (sanciones bursátiles). Encubre acciones de cooptación y corrupción. Facilita el lobby con gobiernos nacionales y regionales. Enfatiza el riesgo a la autoregulación.Aprovecha las debilidades y necesidades socioeconómicas de las comunidades para cooptarlas y dividirlas. Desacredita las críticas de las comunidades y organizaciones (Padilla, 2011).

Lo enunciado por Padilla en el marco de su investigación, no dista de la realidad actual de Colombia, en donde la RSE está estipulada perfectamente como se ha podido constatar en reglamentos jurídicos, pactos empresariales con el gobierno y las comunidades y entre las mismas organizaciones del sector. Pero hoy por hoy, este tipo de convenios y acuerdos se quedan en el papel. En un estudio realizado por Parada y Armando (2013) sobre la RSE de las empresas Cerrejón, Cerro Matoso, Drummond Company y Mineros sa, se demostró que si bien dichas compañías cuentan con una plataforma de gestión sólida y con planteamientos claros y adecuadamente definidos, a nivel social, ambiental e incluso laboral, poseen altas falencias en cumplimiento de los acuerdos que han pactado con el Estado en este campo.

Para demostrar la debilidad empresarial en cuanto al cumplimiento de los estándares de RSE, y a su vez denotar el escaso rendimiento de fiscalización de parte del gobierno, a continuación se mencionarán las «mejores» empresas de Colombia por su excelente desempeño a lo pactado y cometido ambiental y social, y se contrarrestará la información suministrada por la organización que exalta el cumplimiento de sus objetivos, con la realidad actual de las comunidades aledañas a dichos proyectos.

La Cámara de Comercio Colombo Británica (2013), en su página oficial, anunció por medio de un artículo informativo, los denominados «Top 30 de la Responsabilidad Social en Colombia», en el cual exponían las mejores empresas del país en materia de RSE, y por ende han sido merecedoras del premio Lazos, que otorga un reconocimiento a la labor de las organizaciones nacionales y multinacionales en cuanto al desempeño con mejores prácticas medioambientales y programas de apoyo a comunidades: 
Los Programas de RsC de las empresas deben estar enmarcados en los Valores Éticos de las mismas, en los Principios Rectores de Naciones Unidas (Derechos Humanos y Empresas), en el cumplimiento de los más altos estándares internacionales, dentro de la ley y fortaleciendo la institucionalidad y las organizaciones sociales (Cámara de Comercio ColomboBritánica, 2013).

Dentro de estas empresas, dicho organismo hace alusión a las siguientes multinacionales de carácter minero:

1. Anglogold Ashanti: empresa que según la Cámara de Comercio ColomboBritánica (2013) hace parte de dicha lista, debido a su compromiso por el mejoramiento continuo de cada uno de sus procesos, al respeto y cuidado de los recursos naturales y de las comunidades ubicadas en el área de influencia de sus proyectos; la cual define su política ambiental y social como una estrategia integral y garante de compromiso institucional.

El escenario actual de las comunidades adyacentes a los proyectos liderados por esta empresa es completamente diferente a lo que se enuncia en el párrafo anterior. En un artículo publicado por la Red de Hermandad y Solidaridad con Colombia (2009), se compartieron las razones dadas por la Minga de Resistencia Social y Comunitaria delTolima sobre la oposición de este grupo ante el proyecto minero «la Colosa» y dicha empresa. Dentro de los principales argumentos dados en esta manifestación se encontraba la afectación al recurso hídrico que ha generado dicho proyecto, no solo porque se ubica dentro de una zona ambiental protegida, que de hecho es una estrella aluvial que proporciona este líquido vital a 161 nacimientos, sino también por el alto consumo de agua que esta industria necesita, lo que ha generado la escasez para el consumo básico de cerca de 400.000 personas.Adicionalmente también exponen el cómo la puesta en marcha del proyecto ha repercutido en el cambio de la actividad productiva de la región y cómo esta se verá posiblemente afectada (como se ha visto a lo largo de los municipios mineros del país) por la llegada de mayores índices de pobreza y violencia como «en los casos del Sur de Bolívar, La Guajira, el norte del Cauca, el nordeste de Antioquia y Chocó, en donde las comunidades se han convertido en víctimas del desplazamiento forzado, del terror y la violación a sus derechos fundamentales» (Red de Hermandad y Solidaridad con Colombia, 2009). Por su parte, Molano (2008) argumenta que esta multinacional, en todos los territorios colombianos donde cuenta con concesión, ha presentado fuertes demandas por violaciones de derechos humanos a los territorios y líderes comunitarios, lo cual ha llevado a diagnosticar el modus operandi de esta compañía en la mayoría 
de los casos: beneficiarse de la represión como mecanismo para garantizar sus procesos de explotación, y la utilización de la Fuerza Pública como parte de su departamento de seguridad.

2. Cerrejón: de acuerdo con la Cámara de Comercio Colombo-Británica (2013), esta empresa ha posibilitado la reducción de los índices de pobreza en el país gracias a sus programas de RSE, logrando satisfacer las necesidades físicas y básicas humanas de los pobladores en áreas adyacentes a su proyecto.

¿Los programas de RSE del Cerrejón han logrado satisfacer altamente las necesidades físicas y básicas de los pobladores venideros a este proyecto? En una investigación realizada por Villalba (2015) se demostró cómo las actividades ejercidas por esta compañía han generado graves violaciones a los Derechos Humanos de los indígenas ubicados en este territorio, los cuales han tenido que recurrir a instancias internacionales como la Corte Interamericana de Derechos Humanos, en búsqueda del cumplimiento de sus derechos; los casos más reiterativos de vulneración de derechos de estas comunidades son:

- Derecho a la participación, el cual permite la protección de los derechos indígenas sobre los recursos naturales su utilización, administración y conservación.

- Derecho a un medio ambiente sano: la explotación de carbón en el territorio ha originado que organismos como la Procuraduría General de la Nación interpongan acciones populares contra el proyecto debido a los daños a la salud de los habitantes del lugar, causados por el polvillo de carbón y otros químicos y productos provenientes de las actividades mineras que se llevan a cabo en el lugar.

- Derecho a la vida.

- Derecho a exteriorizar, desarrollar e ilustrar sus tradiciones, cultura y ceremonias espirituales y religiosas; a su vez que conservar y resguardar sus sitios sagrados.

A lo anterior, se le suma lo expuesto por Velasco (2013) en una de sus investigaciones, en la cual expone todo el proceso de concesión minera que se ha llevado a cabo en este territorio, y cómo ha sido marcado fuertemente por los atropellos sociales y vulneración de derechos humanos de estas comunidades indígenas, tales como expropiación de tierras, reasentamientos involuntarios, violación a los derechos de prelación de tierras indígenas e indemnizaciones carentes de una adecuada valoración monetaria y compensatoria. 
3. Cerro matoso: la Cámara de Comercio Colombo-Británica (2013) argumenta que este proyecto ha llevado a cabo labores encaminadas al mejoramiento del nivel de calidad de vida de los habitantes del Alto San Jorge, sur del Departamento de Córdoba. En un artículo de prensa publicado por el diario Semana (2012) se hace mención a la situación actual de la comunidad ubicada en el área de influencia del proyecto en mención, en donde se narra cómo las condiciones de la calidad de vida de la comunidad presentan grandes impactos y negativos tras la puesta en marcha de esta obra. A continuación se trae a colación un fragmento de dicho artículo, el cual contextualiza el diario vivir de sus habitantes:

\begin{abstract}
Los pobladores dicen que aguantan el dolor con estoicismo. Aquí no hay un puesto de salud, ni alcantarillado, ni siquiera agua pura para lavar las heridas. Carecen de cualquier servicio público [...] No así los niños semidesnudos, con evidentes signos de desnutrición, que caminan por las seis vías sin pavimentar. En lugar de asfalto están cubiertas de saprolita, un material también de desecho de la mina con alta cantidad de níquel, duro y filudo. Es extraño el niño que no se vea cortado por andar por las calles [...] El alumbrado público es deficiente, no hay alcantarillado y el agua no es potable (Semana, 2012).
\end{abstract}

Acosta, Hincapié y Torres (2012) señalan cómo paradójicamente esta mina pertenece a una de las compañías mineras más importantes del planeta (BHP Billinton), con activos de 72,23 billones de dólares, mientras que los habitantes de este territorio carecen de servicios básicos, cuentan con deficiencias energéticas, de saneamiento y altas cifras de enfermedades producidas por el polvo. Una situación incomprensible puesto que de 30 años que lleva en operación dicho proyecto, el gobierno colombiano nunca ha antepuesto ninguna sanción por incumplimiento a la norma.

En los numerales siguientes, se podrán constatar las realidades de las comunidades que residen en entornos mineros, es decir, se podrán comprobar groso modo, las acciones que enuncian dichas empresas que llevan a cabo, y también las labores por parte del gobierno en cuanto a verificación y control de las actividades ejecutadas por este sector tanto en el ámbito social como en el ambiental.

\title{
1.6. Situación actual del sector minero en la esfera regional
}

El sector minero de Colombia se disputa tres tipos de minerales: el carbón (que ocupa el $0,7 \%$ de las reservas mundiales y el puesto número doce a nivel mundial) (UPME, 2014: 8), el níquel y el oro (Contraloría General de la República, 2014). Claro está, eso no quiere decir que no existan otros 
productos de extracción que sean de interés del sector, sino que estos tres son los que más abundan a lo largo y ancho de la nación. Con el fin de aclarar la situación mencionada en el numeral 3.2 sobre la gestión de RSE de este tipo de industria, a continuación se hará una breve comparación entre las regalías dadas a los departamentos productores de minerales y el contexto de algunos de sus territorios.

Las regalías del subsector carbón están distribuidas básicamente entre los Departamentos de Cesar (37,56\%), La Guajira (34,15\%), Magdalena (4,95\%), Cundinamarca (0,51\%) y Atlántico $(0,26 \%)$. Es necesario aclarar que estos recursos también son distribuidos a otras entidades: FONPET (Fondo Nacional de Pensiones de Entidades Territoriales), Ingeominas, Fondo Nacional de Regalías y, por supuesto, otros Departamentos, ya sea porque participan por explotación o porque reciben algún tipo de compensación (FEDESARROLlo, 2008: 59).

Como se pude dilucidar en el párrafo anterior, algunos departamentos carboníferos del país cuentan con un buen porcentaje de regalías, pero, ¿por qué la población argumenta lo contrario? (INDEPAz, 2012). Se mencionó en el numeral preliminar que upMe (2013: 6) asegura que la percepción de las comunidades y el público en general es que las empresas mineras no hacen inversión social; para demostrar los testimonios de los grupos territoriales más afectados, a continuación se traerá a colación uno de los casos más conocidos a nivel nacional sobre impacto territorial de la extracción minera en la Guajira, el cual cuenta con el conocido mega proyecto minero llamado Cerrejón.

Según Tejada (2015) y el CINEP (2016), varias denuncias se han dado por la comunidad Wayuu, quienes encuentran al proyecto Cerrejón, como el principal culpable ante la sequía de sus fuentes hídricas. Más exactamente de nueve pozos de agua, los cuales garantizaban su acceso al mínimo vital. A su vez, denuncian la pérdida de miles de hectáreas, dentro de las cuales se halla una gran cantidad de afluentes, de los que carecen completamente de acceso y disponibilidad, y por si fuera poco, uno de los resguardos se ubica a unos 500 metros de la mina, el cual se ve directamente afectado por los residuos que esta emana, más las emisiones de polvillo de carbón:

durmiendo con las vibraciones del botadero de desperdicio y de las detonaciones; el resguardo de San Francisco lo atraviesa la vía férrea y una carretera de acceso en la mitad del resguardo [...] También se han presentado accidentes de niños, y cuando han denunciado, «nos dicen que fue por descuido de no leer las advertencias. Pero, ¿y qué vamos a leer? No entendemos mucho español, ¿cómo vamos a entender inglés?» (Tejada, 2015). 
El problema aquí no solo son las regalías, también se trata de rse, lo que deja entrever una gran disputa territorial entre el proyecto minero y la comunidad Wayuu, pero ¿qué ocurre con la gestión estatal? Se supone que este organismo debe ser el mediador y velar por el cumplimiento de leyes y normativas, que no solo protejan los recursos de la nación sino también a sus habitantes. Cuando se habla del hacer en el ciclo PHva, ¿qué entiende el sector minero por RsE?, porque en el planear está excelentemente planteado. Otro de los casos que presenta FEDESARrollo es el departamento de Bolívar, el cual ostenta un $0,91 \%$ de las regalías provenientes del níquel que se extrae de sus suelos:

Las regalías provenientes de la producción de níquel son distribuidas principalmente entre los Departamentos de Córdoba (62\%) y Bolívar ( $0,91 \%)$. El porcentaje restante, al igual que en el caso del carbón, se distribuye entre distintos entes: la CAR, el Fondo Nacional de Regalías y el FONPET, figuran entre los de mayor participación (FEDESARROLLO, 2008: 59).

Investigaciones que permiten comprobar el contexto que actualmente vive el departamento de Bolívar, el cual no solo cuenta con niveles altos de pobreza, sino también con un gran porcentaje de contaminación ambiental, se enuncian a continuación. En un estudio realizado por la Universidad de Cartagena a través de su Grupo de Química Ambiental y Computacional (2007), se detectó que tres poblaciones del sur de Bolívar presentan altos niveles de mercurio no solo en sus ríos, sino también en sus elementos de consumo y sus organismos. Estas poblaciones son Montecristo, La Raya (jurisdicción de este municipio) y Achí. A su vez, en dicha investigación se denunció que especies piscícolas como el moncholo y la mojarra (presentes en la dieta diaria de estas comunidades) representaban una alta acumulación de este metal. Los datos alarmantes se encuentran en las cifras de los niveles de mercurio de los habitantes de estas zonas (Olivero, 2002):

El promedio de mercurio en cabello para una muestra de 1.548 personas de todas las regiones del departamento de Bolívar fue de 1,7 partes por millón (ppm), cuando entidades tales como la Agencia de Protección Ambiental de los Estados Unidos recomiendan que las mismas no sean superiores a $1 \mathrm{ppm}$, en particular en niños y mujeres embarazadas (Grupo de Química Ambiental y Computacional de la Universidad de Cartagena, 2007).

Uno de los problemas que se tiene con el uso del mercurio a nivel industrial, específicamente en el sector minero, es el impacto a la salud que este elemento genera. Los efectos más representativos son malformaciones fetales y problemas de aprendizaje. Como se pudo constatar en dicha in- 
vestigación, las cifras son alarmantes, para pertenecer a un país que está en proceso de eliminación del mercurio tras la promulgación de la Ley 1658 de 2013. Aunque si bien se espera una eliminación completa del uso de este elemento en el sector extractivo para el año 2018, los estragos de la implementación de esta sustancia no se han hecho esperar.

¿Dónde queda la Rse, y la gestión gubernamental en este caso? Se debe recordar que gozar de un ambiente sano y con estándares aceptables que propicien la calidad de vida y la salud, es uno de los derechos fundamentales que se proclamaron desde la instauración de la Constitución Política de 1991 (Constitución Política de Colombia, 1991). En un estudio realizado a los datos de las regalías provenientes de cada subsector minero energético del país (carbón, níquel y oro) (FEDESARrollo, 2008: 61), se llegó a la conclusión que esta actividad tiene un efecto positivo en los departamentos donde ejecute este tipo de labor. Para completar los datos dados por este organismo, en el párrafo siguiente, se darán a conocer las cifras de regalías provenientes del subsector aurífero en los territorios de Antioquia y Chocó:

En el caso del subsector de metales preciosos, el mayor porcentaje de ingresos por concepto de regalías lo reciben los departamentos de Antioquia $(46,09 \%)$ y Chocó $(20,88 \%)$, que al mismo tiempo son los mayores productores de oro. En una proporción mucho menor, aparecen las distribuciones hechas a Caldas $(7,76 \%)$, Bolívar $(5,79 \%)$ y Córdoba (2,34\%) (FEDESARROLLO, 2008: 59).

Pese a que el Chocó cuenta con el 20,88\% de regalías provenientes de este sector, según Quintana y Mojica (2013), el río San Juan, de dicho Departamento, sufre hoy en día los estragos propios de esta labor, dicho afluente, representa el sostenimiento tanto a nivel económico como social de los habitantes de siete municipios chocoanos como: Cértegui, Condoto, Istmina, Tadó, Novita, Sipi y Unión Panamericana. Estas comunidades extraen el agua para su consumo diario, se asean e incluso se alimentan de los peces que anidan allí, pero actualmente este río se encuentra atravesando un proceso de contaminación tras la acción minera que se realiza en el tramo de esta fuente hídrica, la cual está asociada a la contaminación por mercurio, cianuro, vertimientos de material de mina y concentración de grasas y aceites provenientes de dicha actividad industrial. Dicha situación es preocupante no solo por la afectación ambiental notoria que se ha presentado, sino también por los estragos en la salud de los residentes: 
ml, está en su punto límite de alta contaminación» [...] «Es un metal que genera bioacumulación y como metal se acumula en el sistema de todos los seres humanos, al caer este químico a las fuentes hídricas, se metiliza y cuando se vuelve metilmercurio, es un mercurio que se adhiere al sistema del organismo de los peces y al ser consumido por el ser humano tiene una gran afectación en su organismo (Quintana y Mojica, 2013).

Colombia actualmente ocupa uno de los primeros lugares en cuanto a producción de estos tres minerales, lo que ha generado una alta proporción de IED, pero que paradójicamente no se ha visto reflejada en la economía nacional ni en la de los departamentos donde se ejecuta esta labor. Como se pudo apreciar, el contexto de algunos de estos territorios es «miserable», y no tiene mucho que ver con los planes estimulados por la UPME en cuanto a Responsabilidad Social Empresarial. Si bien estos argumentan que han sido destinados ciertos recursos a dicho plan, la pregunta que queda es ¿cómo?, si son notorias las necesidades y condiciones de estas poblaciones.

Como se argumenta en el portal Ola Política (2016), los cinco departamentos más pobres de Colombia son uno de la costa pacífica (Chocó), tres de la costa Caribe (Guajira, Sucre y Córdoba) y uno del suroccidente (Cauca) Allí, los niveles de pobreza se encuentran entre el 63\% y $65 \%$ y los índices de miseria entre el $26 \%$ y $37 \%$, demostrándose esto en la desnutrición de sus niños, mortalidad de este grupo poblacional por causas inapropiadas en la época actual, problemas en cuanto a la accesibilidad al recurso hídrico, inadecuadas condiciones de vivienda y entornos poco saludables.

La diferencia entre los niveles de pobreza de Chocó con Guajira, Cauca, Sucre y Córdoba no supera 1,2 puntos porcentuales. Es una verdadera catástrofe social, que toma ribetes dramáticos al saberse que la miseria de la Guajira es $37,45 \%$, mientras la del promedio de Colombia es $12,3 \%$. Los otros compañeros de viaje de los guajiros en la ruta de la miseria y que tienen indicadores por encima del 30\% son Cauca y Chocó (Ola Política, 2016).

Es paradójico que los departamentos que generan más ganancias por extracción mineral en el país representen los primeros niveles de pobreza y marginalidad de sus poblaciones.

\subsection{El gobierno y su gestión ante la industria extractiva}

Hay realidades que solo ocurren en países con una inadecuada gestión tanto industrial como gubernamental, tal es el caso de Colombia, en el cual ningún organismo acepta la responsabilidad de los impactos generados 
por este tipo de industria (Parada y Bosigas, 2013). Esto ha ocasionado una imagen cada vez más desfavorable del sector minero entre las comunidades padecientes de esta actividad económica (FEDESARrollo, 2014). Según UPME (2013: 6), los representantes del sector privado argumentan que existen dos causas que originan que la implementación de las estrategias estipuladas acerca de que la RSE no se dé satisfactoriamente:

1. Ha sido difícil materializar el impacto positivo de dicha inversión social en las vidas de los individuos afectados por la operación, dado los graves problemas de vulnerabilidad y de bajo nivel de desarrollo humano de las comunidades locales.

2. Aunque el sector de extracción del recurso mineral paga regalías al Estado, los entrevistados del sector privado argumentan que este no ha logrado invertir de manera eficiente los recursos públicos en el territorio para generar procesos de desarrollo local. De acuerdo con el entrevistado [A1], «la comunidad mezcla un poco todo y aun cuando la empresa cumple con pagar las regalías, es deber del Estado invertirlas eficientemente. Cuando esto no sucede, se culpa a la empresa de los males que aquejan a las regiones», por cuanto existe una falta de entendimiento claro sobre cuáles son las responsabilidades que deben ser de las empresas y cuál es el rol del Estado.

Lo anterior solo genera más interrogantes: ¿quién es el responsable de los impactos generados por la extracción minera? Si las empresas de dicho sector argumentan que las causas negativas del desarrollo de su actividad se debe a la vulnerabilidad propia de los territorios donde se ejecuta esta labor y a la inadecuada gestión de las regalías de parte del gobierno; es más que evidente que el principal responsable es el gobierno, ya que este es quien debe ejercer control y vigilancia sobre dicho sector. Si no se ejecuta bien esta tarea, las empresas quedan a la merced de su propia voluntad y hacen la disposición del territorio de la manera más conveniente para ellas.

De acuerdo con Ostau y Niño (2012), el papel de la gobernanza del Estado colombiano ante el sector minero energético es altamente débil, manifestándose esto en la ausencia de control por parte de este organismo tanto en el ámbito laboral como en los resultados en cuanto a los impactos ambientales y sociales generados por el inadecuado manejo de este tipo de industria. Dicha situación se evidencia en la investigación de estos autores con respecto a la RSE de las compañías del sector carbonífero del país, en la cual se demostró que empresas como Drummond no han tenido en cuenta los estragos ambientales y los niveles de conflictividad social que ha ocasionado su labor en el área de influencia de todo lo concerniente a su ciclo productivo y extractivo (Rudas, 2013; Universidad de Bogotá Jorge Tadeo Lozano, 2013). Esto indica que al no poseer un adecuado manejo por parte de los organismos de vigilancia y control estatales, las empresas 
solo cuentan con buenos modelos de rse en el papel, mas no en los hechos, ya que no se ven obligadas a cumplir lo estipulado no solo en su organigrama institucional, sino también en la normatividad y legislación propia del país:

Esta debilidad se manifiesta en la ausencia de control o gobernanza, tanto en el mundo del trabajo como en el impacto ambiental y en la protección de los derechos humanos; dicho control está dominado por los agentes sociales, que tienen la obligación de aplicar la normatividad. La gobernanza se manifiesta, igualmente, en la debilidad del control administrativo y judicial, así como en el control político y legislativo (Ostau y Niño, 2012: 15).

Según Robledo (2010), en una de sus intervenciones ante el Senado de la república de Colombia, dando alusión al tema de la política minera, la nación presenta tres grandes problemas en cuanto a este tema: regalías escandalosamente bajas, exenciones descomunales de impuestos y pésima auditoría. Con respecto a la primera problemática, mencionó que uno de los argumentos del Banco Interamericano de Desarrollo y de la Corporación Andina de Fomento, es que las regalías de productos como el petróleo, carbón y oro son mínimas. En su ponencia, el senador del polo democrático, a su vez, informa que según datos de la Contraloría en una auditoría realizada en compañía de BDo Audit Age sa al contrato Cerromatoso, en este proyecto se han disoluto entre los años 2004 y 200823.118 millones de pesos de regalías, y llevándose esta investigación a los años anteriores, el valor asciende a unos 219.000 millones de pesos.

Con respecto a las exenciones descomunales de impuestos, Robledo (2010) alude a que en el caso de la nación, hay algunos impuestos que no se pagan ya que así se pacta en los contratos. Dentro de los ejemplos dados por el senador, se encuentra el hecho de que este tipo de empresas no rinden cuentas a Industria y Comercio, a la vez que están exentas de la retribución al impuesto predial, sumándosele a esto que en el caso de las fronteras están libres de costear los impuestos a los combustibles. El parlamentario cita al mismo tiempo algunas cifras oficiales de la Contraloría General de la República:

Entre 1995 y el 2007, en solo doce años, en el contrato 078-88, la Drummond no pagó por compensaciones y devoluciones 919.896 millones de pesos, 920.000 para ponerlo en números redondos. Para que ustedes se hagan una idea de cuánta plata es con respecto a ese negocio, representa el $76 \%$ de lo recaudado por regalías, según cifras de la Contraloría General de la República en informes que tengo aquí y que son documentos públicos que cualquiera puede mirar (Robledo, 2010). 
En alusión a su afirmación sobre la pésima auditoría, Robledo (2010) trae a colación de manera textual un informe realizado por la Contraloría de la nación:

Ingeominas no ha realizado desde el 2004, cuando asumió sus funciones de Autoridad Minera delegada una evaluación sistemática y pormenorizada del contenido contractual de cada uno de los contratos clasificados como de Gran Minería, así como de los proyectos de interés nacional pin. No ha hecho una revisión sistemática de cada uno de los contratos, entre otras cosas para saber si se renegocian, o si no se renegocian, en qué términos, etc. [...] Lo cual dio lugar a incumplimientos de cláusulas contractuales y términos de ley, así como deficiencias en la constitución de pólizas y amparos, situación que a la fecha no se ha subsanado a pesar de las observaciones de la CGR [...] (Robledo, 2010).

Este numeral puede resumir la gestión Estatal en cuanto al sector minero energético: ¿cómo no va a crecer la inversión extranjera, si Colombia propicia las mejores condiciones para que esta industria se expanda libremente por la nación? El país actualmente representa un sueño para cualquier multinacional que desee propagar su actividad: las regalías son demasiado bajas, se otorgan privilegios en cuanto al cobro de impuestos y las auditorías que se les hace a las empresas de este sector son prácticamente nulas. ¿Cómo va a generar ingresos esta labor a la economía nacional si ni siquiera el gobierno vela por unas condiciones justas? Se están regalando los recursos de la nación solo a cambio de pobreza y destrucción, ¿qué pasa con la gestión gubernamental?

Queda claro que la gestión de estas empresas a nivel económico es excelente, pero a nivel social y ambiental es soberanamente deplorable, situación que no se justifica, pero sí tiene completa lógica ante un gobierno que «concede» los deseos de este sector por encima de los suyos:

El sector minero colombiano siempre ha sido atacado por la falta de un sano equilibrio entre la generación de incentivos y el establecimiento para el aumento del flujo de ingresos tributarios, más aún cuando proliferan conceptos (Concepto 15766 de 2005, la DiAN) en los que se determina, por ejemplo, acerca de las rentas deducibles, que las regalías constituían un gasto para las empresas del sector extractivo y autorizó su deducción [...] fue así como por efecto directo de la deducción señalada, entre 2005 y 2011 el Estado habría dejado de captar recursos del orden de 1.274 millones de dólares, solamente del sector minero. Esto equivale a una tercera parte del total de las regalías pagadas, suponiendo que la minería a gran escala dedujo el 100 por ciento (Gonzales, 2014: 183). 


\section{DISCUSIÓN}

Pese a poseer unos índices altos de Inversión Extranjera Directa y gran proporción en cuanto a otorgamiento de licencias y titulación minera, el sector extractivo en el país no ha generado el crecimiento económico ideal para que sea una industria fuerte y considerada una de las locomotoras de desarrollo económico de la nación. Esta actividad lleva representando la mirada de los últimos gobiernos desde el año 2002 tras el arribo de Uribe al poder, perpetuando esta noción durante los mandatos póstumos de Santos. La pregunta es: si está comprobado por la misma contraloría y demás organismos de vigilancia, que han sido más los pasivos ambientales y egresos económicos que ha generado este tipo de industria, ¿por qué se sigue llevando a cabo dicha actividad con tanta vehemencia? ¿hay algún interés extra de parte del Estado para seguirla considerando motor de crecimiento económico tras años de constante pérdida y deterioro territorial?

En una entrevista dada para El Espectador, León Teicher, presidente del consorcio El Cerrejón dando respuesta a la pregunta: «¿le seguirá yendo bien al sector en la era Santos?», manifiesta la suerte con la que cuenta Colombia por poseer un presidente como él, a su vez menciona la buena tarea del expresidente Uribe, y en el caso del primero alude "yo creo que se nos volvió a aparecer la Virgen» (Mayorga, 2010).

"La Virgen reencarnada en los últimos dos presidentes colombianos», eso es lo que simbolizan estos mandatarios para la industria minera, ¿pero qué personifican para las poblaciones afectadas tras los impactos acaecidos por la alta concesión de títulos en sus territorios y las fuertes repercusiones que estos han generado en sus entornos? Como se pudo apreciar en el apartado anterior, la oportunidad para unos es la maldición para otros, y en este caso, se hace más que evidente que al no ser las comunidades directamente afectadas las beneficiarias de los frutos emanados por esta actividad, ni tampoco la economía nacional (al contraste en sus ingresos y $\mathrm{PIB})$, son las empresas mismas las que obtienen mayor margen de ganancia casi que de manera única.Y es que no tiene sentido que estas sigan perpetuando su actividad, si solo se generan pérdidas, y no es en vano que en este sector se considere a Santos y Uribe como mediadores y próceres de la patria. No por nada, diversos estudios de organizaciones tanto nacionales como internacionales, han manifestado sus malestares públicos ante la gestión dada a este sector. El PNUD (2011: 42) define algunos riesgos y preocupaciones que suscita la actividad minera en el país: 
- El impacto de mayores recursos externos sobre la apreciación de la moneda colombiana («enfermedad holandesa»).

- La minería no es una actividad generadora de eslabonamientos hacia adelante o hacia atrás en países en desarrollo, y tiende a generar economías de enclave.

- La expedición indiscriminada de licencias y títulos mineros puede tener un efecto perverso sobre los ecosistemas estratégicos y las áreas de protección ambiental.

- Las áreas en concesión para la explotación del subsuelo pueden crear conflictos de uso, debido a la superposición de suelos con aptitud para la explotación agrícola y aquellos destinados a la extracción de minerales.

- La competencia por uso del suelo y subsuelo puede convertirse en una forma soterrada de presión y despojo de la tierra.

- La variabilidad y cambio climático conjugadas con las explotaciones mineras pueden disminuir la disponibilidad del agua hacia el futuro.

- La actividad minera puede vulnerar los derechos de la población rural cuando no se cumplen los procesos de consulta previa.

Como se ha podido identificar, se presenta un escenario prácticamente idóneo para la industria extractiva en Colombia: un gobierno con capacidades restringidas en cuanto a vigilancia y control, con una presencia parcial en los territorios donde se lleva a cabo esta actividad, y con limitaciones institucionales que no deberían ser pretexto para brindar una adecuada protección y custodia al cumplimiento de los Derechos Humanos de sus nacionales. No es lógico que se den más garantías a un sector económico que a los colombianos, y esto se evidencia en las altas cifras de expedición de títulos, en la cantidad de casos de territorios afectados por esta industria y en las misérrimas proporciones de ganancia económica generadas por esta labor, situación que demuestra no solo una inadecuada gestión empresarial por parte de estos (tras los altos impactos ambientales, sociales y culturales que se generan en los territorios incursionados, lo cual, a su vez, representa una condición ilegal, ya que el país cuenta con un marco normativo y constitucional claro, que obliga a este tipo de industria a generar sus actividades de manera sostenible tanto con los recursos naturales como con las comunidades), sino también una incorrecta gestión gubernamental (no se llevan a cabo los mecanismos de vigilancia y control adecuados ante este tipo de industria y no se vela por el bienestar de la 
comunidad, ya que se permite que los primeros impacten de manera descomunal a los territorios).

\section{CONCLUSIONES}

¿Cómo se va a hablar de una correcta gestión estatal si el Estado concede cualquier tipo de dádivas al sector minero; si paralelo a implementar leyes y plantear normas y mandatos, se forjan estrategias para burlarlas y tergiversar la información; si, como se pudo evidenciar, no se ejecutan de manera adecuada los mecanismos de vigilancia y control?

El problema de la indebida gestión de la industria minera del país es responsabilidad del Estado, ya que si este es flexible y «generoso» con dicho sector, las empresas se aprovechan: no por nada la inversión externa se ha incrementado tanto en el ámbito de la extracción minera. Si este primer organismo no desarrolla una debida gestión, mucho menos los segundos van a considerar implementar adecuados mecanismos en cuanto a responsabilidad ambiental y social, porque generaría gastos innecesarios debido a que si no existe sanción, vigilancia y control ante los actos inapropiados, resulta una pérdida de tiempo y recursos solventar los impactos territoriales. De todas maneras, el desarrollo de esta labor se seguirá ejecutando bien sea dando cumplimiento a las normas o no.

En términos de la minería y en la forma en la que el país ha venido permitiendo que se desarrolle dicha actividad, deja de lado la posibilidad de que se generen indicadores de desarrollo para las comunidades que tienen que soportar la carga de este modelo neoextractivista y de paso la posibilidad de apalancar la equidad que tanto promulgan los gobiernos de turno. La muerte ecosistémica, la muerte cultural, la muerte territorial que a su paso deja la minería en el país, es una clara evidencia de la concentración de riqueza en algunos sectores despojando a otros de la posibilidad de una vida digna.

Y fuertemente ligado al capitalismo necropolítico, las infinitas brechas y asimetría de poderes entre los países del norte y el sur, y en este caso entre las multinacionales extractivistas y las comunidades. Como se mencionaba, la UPME (Unidad de Planificación Minero Energética) atribuye a graves problemas de vulnerabilidad y de bajo nivel de desarrollo humano de las comunidades locales, el hecho de que no se logre evidenciar fuertemente el impacto de la «inversión social» de las grandes empresas mineras. Entonces caben las siguientes preguntas: ¿son entonces las comunidades 
responsables de ser vulnerables y tener bajo nivel de desarrollo humano? ¿Son culpables las comunidades de que por esta situación, no se evidencien los impactos positivos de la «inversión social» de las empresas mineras? Esto nos llevaría entonces a pensar en si realmente el país le debe seguir apuntando tan fuertemente como hasta ahora lo ha hecho a las políticas de desarrollo mineroenergético que siguen reproduciendo las inequidades de un modelo de crecimiento económico que busca solo el bienestar para aquellos que ya lo tienen.

\section{BIBLIOGRAFÍA}

Acosta, J., Hincapié, L. y Torres, L. (2012): «Desarrollo económico sostenible: perspectiva desde la industria minera colombiana», Quid, 18, pp. 53-58. Bermúdez, R. E., Rodríguez,T., y RoA,T. (2012): "Ámbitos de análisis e impactos de la minería en la vida de las mujeres. Enfoque de derechos y perspectiva de género». Disponible en: http://desterresminees.pasc.ca/wp-content/uploads/2015/11/Bermudez-Rico-et-al-2011-Mujer_y_Mineria.PDF [Consultado el 25 de noviembre de 2016]

Cámara de Comercio Colombo-Británica (2014): «Los Top 30 de la Responsabilidad Social en Colombia», Programa de Responsabilidad Social Empresarial Lazos. Disponible en: http://www.colombobritanica.com/ web/la-camara/responsabilidad-social/libro-los-top-30-de-la-rse-encolombia/284-los-top-30-de-la-responsabilidad-social-en-colombia.html [Consultado el 13 de diciembre de 2016]

Celedón, N. (2015): «Colombia es un país de alta accidentalidad minera», Portafolio. Disponible en: http://www.portafolio.co/economia/finanzas/colombia-pais-alta-accidentalidad-minera-29618 [Consultado el 25 de noviembre de 2016]

Colombia.com (2016): «Economía». Disponible en: http://www.colombia. com/colombia-info/informacion-general/economia/ [Consultado el 13 de diciembre de 2016]

CINEP (2016): Minería, conflictos agrarios y ambientales en el sur de la Guajira, Colombia, CINEP/Programa por la Paz.

Constitución Política de Colombia (1991): Nueva Constitución Política de Colombia, Colombia, Bogotá, Editorial Aster.

Contraloría general de la RePública (2014): Minería en Colombia: daños ecológicos y socioeconómicos y consideraciones sobre un modelo minero alternativo, Bogotá, Imprenta Nacional de Colombia. 
Datosmacro.com (2016): «En julio se elevó el IPC en Colombia», Expansión. Disponible en: http://www.datosmacro.com/ipc-paises/colombia [Consultado el 13 de diciembre de 2016]

Fedesarrollo (2008): «La minería en Colombia: impacto socioeconómico y fiscal, Bogotá». Disponible en: http://www.fedesarrollo.org.co/wp-content/uploads/2011/08/La-miner\%C3\%ADa-en-Colombia-Informe-de-Fedesarrollo-2008.PDF [Consultado el 13 de diciembre de 2016]

- (2014): «Minería y medio ambiente en Colombia. Bogotá». Disponible en: http://www.repository.fedesarrollo.org.co/bitstream/11445/335/1/Repor_ Junio_2014_Martinez.PDF [Consultado el 04 de enero de 2017]

FERNÁNDEZ, J. y VALENCIA, M. (2010): Libre comercio y minería en Colombia, Bogotá, Red Colombiana de Acción frente al Libre Comercio.

GARCíA,A. (2016). «En el 2016, la canasta familiar no dará respiro al bolsillo». Disponible en: http://www.elpais.com.co/elpais/economia/ noticias/2016-canasta-familiar-dara-respiro [Consultado el 29 de noviembre de 2016]

García, F. (2014): «10 años de empleo, crecimiento y sectores», Dinero. Disponible en: http://www.dinero.com/opinion/columnistas/articulo/10anos-empleo-crecimiento-sectores/193833 [Consultado el 24 de noviembre de 2016]

Gobierno de Colombia (2010): Ley N. ${ }^{\circ} 1382$ de 2010 por la cual se modifica la Ley 685 de 2001 Código de Minas. Congreso de Colombia, Bogotá, 9 de febrero de 2010. Disponible en: http://www.bdlaw.com/assets/htmldocuments/Colombia\%20-\%20Ley\%20No.\%201382\%20de\%202010\%20 Amendments\%20to\%20the\%20Mining\%20Law.PDF [Consultado el 13 de diciembre de 2016]

Gonzales, N. (2014): La concesión minera en Colombia: un análisis desde el marco normativo y regulatorio frente a los principios de seguridad y estabilidad jurídica, Universidad Colegio Mayor de Nuestra Señora del Rosario Facultad de Jurisprudencia, Bogotá, Colombia.

Grupo de Química Ambiental y Computacional de la Universidad de Cartagena (2007): «El mercurio afecta al sur de Bolívar», Cienciágora, experiencia, renovación y esperanza de la ciencia en Colombia. Disponible en: http://cienciagora.com.co/novedades_de_ciencia_y_tecnologia/el-mercurio-afecta-al-sur-de-bolivar/246.html [Consultado el 12 de diciembre de 2016]

INDEPAZ (2012): Minería: ¿del extractivismo a una nueva era?, Bogotá, Espacio Creativo. 
Iregui, A. M., Melo, L.A. y Ramírez, M.T. (2011): «Diferenciales salariales en el mercado de trabajo formal en Colombia: evidencia a partir de una encuesta a nivel de firma», en López Enciso, E. y Ramírez, M.T. (2011): Formación de precios y salarios en Colombia Tomo II (pp. 715-754), Banco de la República, Colombia.

MalaVer, F. (2002): «Dinámica y transformaciones de la industria colombiana», Cuadernos de economía, 36, pp. 273-325.

Mayorga, D. (2010): «La Virgen reapareció con Santos», El Espectador. Disponible en: http://www.elespectador.com/impreso/negocios/articuloimpreso-223155-virgen-reaparecio-santos [Consultado el 25 de noviembre de 2016]

Ministerio de Minas y Energía (2009): «Colombia Minera. Desarrollo Responsable. Así es la minería», República de Colombia. Disponible en: http:// www.simco.gov.co/Portals/0/archivos/Cartilla_Mineria.PDF [Consultado el 13 de diciembre de 2016]

Molano, J. (2008): "Anglo Gold Ashanti: la voracidad de las transnacionales de la muerte y el saqueo", en Houghton, J. (ed.) (2008): La Tierra contra la muerte: Conflictos territoriales de los pueblos indígenas en Colombia (pp. 381-931), Colombia, Centro de Cooperación al Indígena CECoIN.

Ola Política (2016): «Los cinco Departamentos más pobres de Colombia», Ola Política. Disponible en: http://www.olapolitica.com/content/loscinco-departamentos-m\%C3\%A1s-pobres-de-colombia [Consultado el 13 de diciembre de 2016]

Olivero, J. (ed.). (2002): El lado gris de la minería del oro: la contaminación con mercurio en el Norte de Colombia, Cartagena, Editorial Universitaria.

Ostau, D. F y NiÑo, C. L. (2012): «La responsabilidad social empresarial en las empresas del sector carbonífero colombiano: lecciones y experiencias de las transnacionales mineras en el marco de los estándares internacionales determinados por la Organización Internacional del Trabajo», Diálogo de saberes, 36, pp. 8-98.

Padilla, C. (2011): «Impactos ambientales y socioeconómicos de la minería. Responsabilidad social empresarial en minería: el zorro cuidando a las gallinas», Revista Semillas, 42/43. Disponible en: http://semillas.org.co/ es/revista/responsabilidad-social-empresarial-en-miner [Consultado el 25 de noviembre de 2016] 
PARAda, J. E. y Bosigas, J.A. (2013): «Responsabilidad social empresarial en el sector minero de Colombia», Revista Inquietud Empresarial, XIII(2), pp. 55-70.

PNud Colombia (2011): Colombia rural, razones para la esperanza. Informe Nacional de Desarrollo Humano 2011, Programa de las Naciones Unidas para el Desarrollo, Bogotá.

Quintana, S. y Mojica, M. (2013): «El río San Juan, una víctima más de la minería en el Chocó». Expresión digital. Disponible en: http://expresiondigital.ucp.edu.co/?p=5546 [Consultado el 13 de diciembre de 2016]

Quiroga, A. (2012): Construcción del territorio minero campesino en el nordeste de Antioquia, Colombia, movimientos socioterritoriales $y$ Derechos Humanos en contra del modelo económico multinacional 1970-2010, Universidad Nacional de Colombia, Bogotá, Colombia.

Red de Hermandad y Solidaridad con Colombia (2009): «La Colosa y la multinacional Anglo Gold Ashanti». Disponible en: http://www.redcolombia.org/ index.php/regiones/centro/eje-cafetero/663-la-colosa-y-a-la-multinacional-anglo-gold-ashanti.html [Consultado el 13 de diciembre de 2016]

Robledo, J. E. (2010): «Los atropellos de la gran minería en los gobiernos de Uribe y Santos», Polo Democrático Alternativo. Disponible en: http:// moir.org.co/Los-atropellos-de-la-gran-mineria.html [Consultado el 25 de noviembre de 2016]

RudAs, G. (2013): «Notas sobre el estado de la minería de carbón a gran escala en Colombia», Fondo Nacional Ambiental. Disponible en: http:// www.foronacionalambiental.org.co/wp-content/uploads/2014/01/40policy-ambiental.PDF [Consultado el 04 de enero de 2017]

SAADE, M. (2013): Desarrollo minero y conflictos socioambientales: los casos de Colombia, México y el Perú, Santiago de Chile, Naciones Unidas.

SEmana (2012): "Cerro Matoso: mina rica, pueblo pobre». Disponible en: http://www.semana.com/nacion/articulo/cerro-matoso-mina-rica-pueblo-pobre/262408-3 [Consultado el 12 de diciembre de 2016]

SERVICIO DE INFORMACIÓN INDÍgENA (2004): «La minería y sus impactos». Boletín informativo,57, pp.1-29.Disponibleen:https://es.scribd.com/doc/219554197/ Serv-57-Mineria [Consultado el 13 de diciembre de 2016]

TEJADA, C. (2015): «Colombia: sequía y hambruna por minería en La Guajira», Resumen. Disponible en: http://www.resumenlatinoamericano. org/2015/06/04/colombia-sequia-y-hambruna-por-mineria-en-la-guajira/ [Consultado el 13 de diciembre de 2016] 
Unidad de Planeación Minero Energética (2013): «Responsabilidad Social para la Minería en Colombia». Disponible en: http://www1.upme.gov.co/sites/default/files/forum_topic/3655/files/responsabilidad_social_mineria_colombia.PDF [Consultado el 12 de diciembre de 2016]

Unidad de Planeación Minero Energética (2014): «El sector minero colombiano actual». Disponible en: http://www1.upme.gov.co/sites/default/files/ forum_topic/3655/files/sector_minero_colombiano_actual_trayectoria_organizacion_industrial_distancia_frontera_tecnologica.PDF [Consultado el 03 de enero de 2017]

Universidad de Bogotá Jorge TAdeo Lozano (2013): «Evaluación ambiental del impacto causado por la barcaza TS-115 en el área de anclaje de Puerto Drummond, Ciénaga Magdalena, Caribe Colombiano». Disponible en: http://www.drummondltd.com/wp-content/uploads/3.-InformeFinaluJTL-Completo.PDF [Consultado el 04 de enero de 2017]

VÁsQuEZ, E. (2011): «Absentismo laboral por causa médica en trabajadores del área operativa de una compañía de extracción de minerales en Colombia, 2011», Medicina y Seguridad del Trabajo, 59(230), pp. 93-101.

Velasco, J. (2013): "Negociando la tierra: empresas extranjeras, minería a gran escala y derechos humanos», Estudios Socio-Jurídicos, 16(11), pp. 289-314.

Villalba, C. G. (2015): Minería irresponsable en el Cerrejón y efectos sobre la Nación Wayúu: una perspectiva para la justicia internacional de los Derechos Humanos, Universidad Militar Nueva Granada, Bogotá. 